
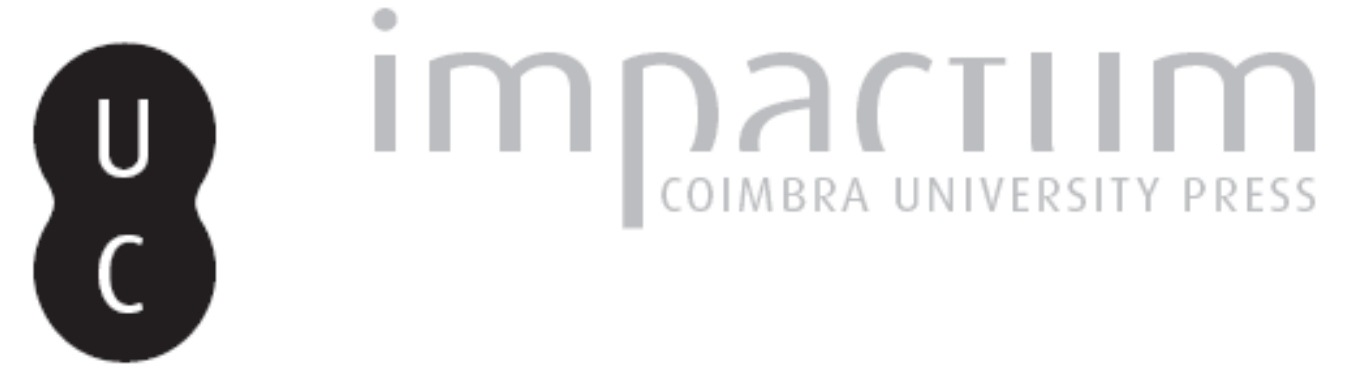

\title{
Novos elementos sobre o templo romano de Almofala
}

Autor(es): $\quad$ Frade, Helena

Publicado por: Imprensa da Universidade de Coimbra

URL persistente:

URI:http://hdl.handle.net/10316.2/45547

DOI:

DOI:https://dx.doi.org/10.14195/1647-8657_29_5

Accessed : $\quad$ 26-Apr-2023 13:52:51

A navegação consulta e descarregamento dos títulos inseridos nas Bibliotecas Digitais UC Digitalis, UC Pombalina e UC Impactum, pressupõem a aceitação plena e sem reservas dos Termos e Condições de Uso destas Bibliotecas Digitais, disponíveis em https://digitalis.uc.pt/pt-pt/termos.

Conforme exposto nos referidos Termos e Condições de Uso, o descarregamento de títulos de acesso restrito requer uma licença válida de autorização devendo o utilizador aceder ao(s) documento(s) a partir de um endereço de IP da instituição detentora da supramencionada licença.

Ao utilizador é apenas permitido o descarregamento para uso pessoal, pelo que o emprego do(s) título(s) descarregado(s) para outro fim, designadamente comercial, carece de autorização do respetivo autor ou editor da obra.

Na medida em que todas as obras da UC Digitalis se encontram protegidas pelo Código do Direito de Autor e Direitos Conexos e demais legislação aplicável, toda a cópia, parcial ou total, deste documento, nos casos em que é legalmente admitida, deverá conter ou fazer-se acompanhar por este aviso.

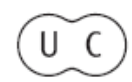


FACULDADE DE LETRAS

INSTITUTO DE ARQUEOLOGIA

CONIMBRIGA

VOLUME XXIX

UNIVERSIDADE DE COIMBRA

1990 


\section{HELENA FRADE}

Arqueóloga. Técnica Superior da Divisão de Arqueologia da Zona Centro (IPPC).

\section{NOVOS ELEMENTOS SOBRE O TEMPLO ROMANO DE ALMOFALA}

«Conimbriga», XXIX, 1990, 91-101

RESUMO: Após relembrar a história do monumento, a Autora dá miúda conta dos seus actuais vestígios, que descreve, e apresenta uma hipótese de interpretação do primitivo templo romano (prostilo tetrastilo) aí existente, dedicado a uma divindade clássica. Esse templo poderia ter estado integrado numa povoação com certa importância.

RÉSUMÉ: Après avoir esquissé l'histoire du monument, l'Auteur fait une description de ses vestiges actuels et présente une hypothèse d'interprétation du primitif temple romain, sûrement dédié à une divinité du panthéon latin. Ce temple était très probablement intégré dans un contexte urbain assez important à l'époque. 
(Página deixada propositadamente em branco) 


\section{NOVOS ELEMENTOS SOBRE O TEMPLO ROMANO DE ALMOFALA}

A Torre de Almofala ergue-se num pequeno planalto existente no cimo de uma colina pertencente à freguesia de Almofala, concelho de Figueira de Castelo Rodrigo, distrito da Guarda () (Est. 1).

O sítio da Torre é conhecido, na região, como Casarão da Torre, Torre dos Frades, Torre de Aguiar ou Torre das Águias. Os documentos mais antigos referem-se-lhe sob o nome de Turris Aquilaris.

$\mathrm{O}$ acesso ao monumento pode ser feito por um caminho de terra batida, que surge ao lado esquerdo da estrada que liga Figueira de Castelo Rodrigo a Almofala, em frente da barragem municipal. Este caminho é bordejado por terrenos ocupados por vinhedos e pomares ou utilizados para cultivo de cereais.

A Torre encontra-se implantada numa zona xistosa ( $\left.{ }^{2}\right)$.

A Ribeira de Rodeios, pelo lado norte, e a Ribeira de Aguiar, pelos lados oeste e sul, rodeiam o pequeno monte do Casarão da Torre.

O imóvel encontra-se classificado como Monumento Nacional pelo Dec.-Lei 129/77, de 29 de Setembro, sob a designação de Torre de Almofala.

A imponência das ruínas que restam da Torre tem alimentado as lendas de tesouros e mouras encantadas que ainda hoje se encontram bem vivas no imaginário popular.

As referências bibliográficas sobre esta construção que, com certa majestade, se ergue no alto da colina, não são muito abundantes.

As mais antigas alusões à Torre aparecem-nos em documentos medievais relacionados com o Convento de Santa Maria de Aguiar. E

(1) Na Carta Militar n. ${ }^{\circ}$ 162, na escala 1/25.000, edição de 1'946 dos Serviços Cartográficos do Exército, o local denominado "Casarão da Torre" apresenta as seguintes coordenadas: UTM 305,5; 434, 2. A altitude média do sítio é de $638 \mathrm{~m}$.

(2) Vide Carvalhos A, 1959: 10 e Frade 1990. 
ainda incerta a data da fundação deste mosteiro, que Viterbo diz ter sido, primitivamente, de obediência beneditina e com sede na Granja da Torre muito antes de 1150 (VITERBO 1983: 145).

É, contudo, numa carta de doação de Fernando II, rei de Leão, datada de 1176, que pela primeira vez nos aparece referência concreta à Turris Aquilaris. Nesta carta Fernando II doa ao abade Hugo, do Mosteiro, o lugar chamado granjam Turris Aquilaris (AZEVEDO 1910: 4-5).

Do teor desta doação parece poder inferir-se que existiria no local uma pequena povoação. Esta povoação, que após a doação tomou o nome de Torre dos Frades, aparece mencionada no "Numeramento" de 1527, com 21 fogos.

A aldeia da Torre dos Frades terá sido destruída pelas tropas espanholas, na altura da batalha de Castelo Rodrigo, durante a Guerra da Restauração, e a partir daí o sítio ficou definitivamente abandonado.

Só muito recentemente, já neste século e sobretudo a partir da década de 60 , é que o monumento foi alvo de atenção e estudo por parte de arqueólogos e historiadores, sendo contudo diversas as atribuições cronológicas e funcionais que para ele têm sido propostas $\left({ }^{3}\right)$.

\section{O monumento e a sua história}

A Torre destaca-se na paisagem, quer pela sua localização, quer pela altura de paredes que ainda conserva. Em seu redor e nas encostas da colina viradas a nascente e a sul são ainda bem visíveis os restos de muros que definem compartimentos, casas e ruas, vestígios da antiga aldeia da Torre dos Frades. As ruas parecem seguir uma orientação este/oeste, igual à da Torre. É provável que estes vestígios também existam nos lados oeste e norte embora mais destruídos.

Orientada a nascente, possui um podium construído com grandes silhares e rematado por uma cornija, que o emoldura. O podium tem uma altura superior a $2 \mathrm{~m}$, é bem visível nos lados norte, sul e oeste (Fots. 1, 2 e 3). Na parede leste não é visível qualquer vestígio, dando a impressão de ter sido aqui abruptamente truncado. Existem ainda quatro cunhais feitos com grandes blocos de granito. As paredes norte, oeste e sul, construídas em cima do podium, são feitas de placas de xisto

(3) Sobre as várias interpretações do monumento, dadas pelos diversos autores, vd. FRADE 1990. 
unidas com forte argamassa de cal. Estas paredes encontram-se bem solidárias com os cunhais NW e SW. A parede leste (Fot. 4), com um aparelho bem diferente, é feita com blocos irregulares de xisto e granito, unidos por barro amassado. A construção dos cunhais NE e SE é tecnicamente inferior à que foi utilizada nos cunhais NW e SW, pretendendo, contudo, ser uma imitação destes.

As paredes $\mathrm{N}$ e $\mathrm{S}$ da Torre de Almofala ruiram parcialmente, entulhando o interior do monumento.

A parede $\mathrm{W}$, onde se abrem duas janelas pequenas, é, de todas, a que apresenta maior altura e se encontra em melhor estado de conservação.

A parede leste, onde se abrem duas janelas e uma porta, é ainda bastante alta e apresenta sérios sinais de ruína.

O local onde hoje crescem arbustos e se erguem as ruínas do Casarão da Torre foi palco de vários séculos de história. Os dados que possuímos permitem algumas reflexões sobre o monumento e a sua evolução.

O abandono da Torre, bem como da aldeia da Torre dos Frades, deve datar da última grande destruição que sofreu no séc. XVII, durante a Guerra da Independência (GARCIA 1965: 231). É a partir desta altura que os documentos deixam de se lhe referir. A Torre, que na altura devia funcionar como atalaia, foi sujeita a um violento ataque e ficou bastante danificada. Situada num ponto estratégico, do ponto de vista militar, ela deve ter sido utilizada como posto de vigia pelo menos desde o séc. XVI. É desta época a construção da parede nascente onde se localizava a entrada para o edifício, bem como alguns dos muros e calçadas postos a descoberto ao longo da parede norte do monumento (Est. 2, Fot. 5) $\left({ }^{4}\right)$.

As modificações operadas no séc. XVI, ou possivelmente antes, foram as responsáveis pela redução do tamanho primitivo do edifício. Assim a construção da parede nascente levou à destruição de parte do podium e à mudança no acesso ao seu interior. Nessa altura, a Torre terá ficado reduzida ao tamanho que ainda hoje conserva, com três andares, a que correspondem a porta e as janelas existentes nessa parede. Devem datar da mesma remodelação as duas janelas da parede poente. É provável que nas paredes norte e sul se abrissem também janelas ou varandas, a julgar por algumas pedras aparelhadas, de granito, que

$\left(^{4}\right)$ Estes muros, relacionados com a estrutura defensiva da altura em que a Torre foi atalaia, não são todos da mesma época e pertencem a diversas reconstruções que o monumento sofreu. Alguns utilizam mesmo as calçadas, mais antigas, comò fundação.

Conimbriga, 29 (1990), 91-101 
foram encontradas debaixo das paredes que caíram no interior do monumento, e pelas informações orais de pessoas mais idosas $\left(^{5}\right)$. No reboco da face interna da parede poente existe ainda o registo de uma escada de acesso ao último andar.

De fundação romana, o edifício foi originalmente utilizado como templo. Durante o espaço de tempo compreendido entre a Alta Idade Média e a altura em que foi remodelado, terá conservado a sua traça original. Não se sabe, contudo, qual a sua funcionalidade. Terá sido o local onde primeiro se fundou o Mosteiro de Santa Maria de Aguiar, como é referido por vários autores (COUTO 1927: 18)? O antigo templo terá sido convertido em local de oração dos monges? Ou terá tido neste longo espaço de tempo a função de atalaia ou posto de vigia que lhe viemos a conhecer mais tarde? A sua localização, num ponto estratégico e numa zona de recontros e disputas entre Cristãos e Muçulmanos e entre Portugueses e Leoneses, parece sugeri-lo. Para estas questões ainda não se obtiveram respostas. Espera-se que as escavações que aqui se vêm efectuando lancem alguma luz sobre o assunto $\left(^{(}\right)$.

\section{O templo romano}

Se é difícil saber qual a utilização do edifício nos conturbados tempos medievais, é no entanto mais fácil falar das características e da planta do primitivo templo romano, que, apesar das mutilações, conserva muito da sua estrutura inicial.

De planta rectangular, o templo tinha sensivelmente $16,30 \mathrm{~m}$ de comprimento e $8,15 \mathrm{~m}$ de largura, que corresponde às medidas romanas de 55 pés no comprimento e 27,5 pés na largura. Note-se que estas medidas são alguns metros inferiores às do templo do forum Paviano de Conímbriga (ALARCÃO e ETIENNE 1977: 90). O podium, que ainda conserva as paredes $\mathrm{N}, \mathrm{S}$ e $\mathrm{W}$, tem uma altura de $2,65 \mathrm{~m}$ ( 9 pés). Para o construir, procedeu-se do seguinte modo: sobre a rocha-base foi posta uma camada niveladora de fragmentos de xisto unidos com alguma

${ }^{5}$ ) Segundo essas informações, até aos anos 40 a Torre ainda conservava as paredes intactas. Terão caído durante o ciclone de 1941.

$\left.{ }^{(}\right)$O estudo e definição cronológica e funcional da Torre e da área circundante estão inseridos num programa mais amplo que visa a recuperação do imóvel pelo IPPC. Os trabalhos foram iniciados em 1989, com limpeza e escavação. Este artigo é o resultado das observações efectuadas durante as duas primeiras campanhas de escavação. 
argamassa. Sobre esta camada foram assentes silhares regulares de granito, de forma paralelepipédica, com 110 X 60 X $30 \mathrm{~cm}$, dispostos no sentido da largura. Sobre eles havia uma outra fiada de silhares mais pequenos (100 X 40 X $40 \mathrm{~cm}$ ), na qual assenta a moldura, com $42,5 \mathrm{~cm}$ de altura, que define a base do pódio (Est. 2, Fot. 6) ${ }^{7}$ ).

Esta moldura suporta três fiadas de silhares regulares, com 90 X 60 X $45 \mathrm{~cm}$, sobre a última das quais está uma cornija, também com $42,5 \mathrm{~cm}$ de altura, que constitui o remate superior do podium. Este perfil é semelhante aos perfis dos templos de Évora (HAUSCHILD 1986: 94, fig. 1) e Idanha-a-Velha (MANTAs 1988: 430) ${ }^{8}$ ).

As três fiadas de silhares existentes entre a moldura de base e a cornija têm técnicas construtivas diferentes. Na primeira fiada, posta em cima da moldura, todos os silhares foram colocados no sentido da largura, formando uma camada uniforme, quer na face externa do podium quer na face interna. Nas outras duas fiadas, os silhares foram postos alternadamente no sentido do comprimento e da largura. Por isso, na face interna do podium ficaram espaços vazios, que foram preenchidos com placas de xisto, unidas por uma forte argamassa de cal (Est. 3).

Junto das paredes internas do podium e encostado a elas, existe um pequeno muro que foi constuído utilizando a mesma técnica dos enchimentos atrás referidos: placas de xisto fortemente argamassadas. Este muro, que serviria possivelmente de reforço ao podium, também existe junto das fundações romanas postas agora a descoberto, dando maior solidez a todo o monumento. Com cerca de $50 \mathrm{~cm}$ de largura, corre ao longo das referidas paredes e atinge a altura da primeira fiada de silhares colocada sobre a moldura de base.

Sobre a cornija que remata o podium erguem-se as paredes $\mathrm{N}, \mathrm{S}$ e $\mathrm{O}$ do templo. Foram construídas também com placas de xisto argamassadas. O tipo de aparelho e a argamassa destas paredes são, em tudo, semelhantes aos do muro de reforço do podium e aos dos enchimentos das suas paredes internas (Est. 3). Não há, numa primeira análise, qualquer diferença construtiva a assinalar. Além disso, as partes do monumento que foram construídas com este aparelho estão, nalguns sítios,

(7) Pensamos que na época romana o nível do solo seria ligeiramente abaixo desta moldura de base, deixando ver a parte superior dos silhares que a suportam.

${ }^{8}$ ) As dimensões destes templos, medidas no exterior do podium, são (comprimento $\mathrm{X}$ largura):

Conímbriga - $19 \mathrm{~m} \mathrm{X} \mathrm{11,80} \mathrm{m.}$

Évora - 24, $60 \mathrm{~m} \mathrm{X} \mathrm{14,19} \mathrm{m.}$

Idanha-a-Velha $-17,6 \mathrm{~m} \mathrm{X} \mathrm{9,2} \mathrm{m.}$ 
fortemente imbricadas com os silhares de granito do podium. Tudo isto leva-nos a propor a contemporaneidade entre a construção do podium e das paredes feitas de placas de xisto unidas com argamassa de cal, na época romana.

A parede poente, toda construída desta maneira, tem a largura do monumento e uma altura de cerca de $8 \mathrm{~m}$. A $\mathrm{N}$ e a $\mathrm{S}$, existem apenas restos das paredes, junto aos cunhais NW e SW. Estes cunhais são construídos com silhares regulares de granito e apresentam-se bem solidários com as paredes e com o podium.

A actual parede nascente terá sido construída após destruição de parte do podium e a diminuição do tamanho do monumento. O seu alicerce é, no entanto, semelhante aos alicerces do resto do monumento e utiliza a mesma técnica construtiva. Poder-se-á pensar que também terá sido construído na época romana e que sobre ele estaria a parede nascente da cella. Assim, as dimensões interiores da cella corresponderiam àquilo que ainda hoje é visível do antigo templo romano: $8,40 \mathrm{~m}$ de comprimento por $5,45 \mathrm{~m}$ de largura. Somente futuras escavações poderão confirmar esta hipótese.

$\mathrm{O}$ acesso ao edifício era feito através de uma escadaria que se desenvolvia a partir da fachada nascente (Ests. 2 e 4). Dela apenas restam as fundações, constituídas por silhares de granito semelhantes aos dos alicerces do podium. Igualmente a técnica construtiva é semelhante, com uma "cama" de placas de xisto e alguma argamassa, disposta sobre a rocha-base e servindo de suporte aos silhares. Também aqui existe o muro de reforço, feito com placas de xisto e argamassa, que acompanha toda a face interna das paredes (Fot. 7).

Os silhares das fundações do podium e da escadaria têm dimensões semelhantes $(110$ X $60 \times 30 \mathrm{~cm})$. No entanto, a sua colocação foi feita de modo diferente. No podium foram postos transversalmente, originando que a largura do alicerce tenha a mesma medida do comprimento do silhar. Na escadaria, os silhares estão dispostos longitudinalmente, tendo a largura do alicerce a medida da largura dos silhares. Isto dever-se-à, certamente, à necessidade de suportar, no caso do podium, paredes mais altas que necessitam de alicerces maiores e mais fortes $\left({ }^{9}\right)$.

Do pavimento da cella não foram encontrados, até ao momento, quaisquer vestígios. A utilização do interior do podium, de que apenas se conhece o seu uso como o primeiro dos três pisos com que a Torre

$\left({ }^{9}\right)$ As fundações do edifício têm $1,50 \mathrm{~m}$ de largura. 
ficou, após as remodelações do séc. XVI (FRADE 1990), poderá ter levado à destruição dos pavimentos romanos. No entanto, indícios ainda existentes nas paredes N, S e W sugerem algumas hipóteses. Assim, pode pensar-se que sobre as saliências dos silhares da fiada que suporta a cornija poderiam assentar grossas traves de madeira, criando-se assim uma estrutura que suportaria o pavimento. Este deveria situar-se ao mesmo nível que a parte superior da cornija do podium e poderia ser constituído por lajes de granito.

É possível que tivesse havido uma cripta sob a cella, aproveitando-se assim o espaço, com cerca de $1,80 \mathrm{~m}$ de altura $\left({ }^{10}\right)$, correspondente às três fiadas de silhares do podium.

Estamos, pois, perante um templo de planta clássica, com celia rectangular e que não se enquadra nos templos perípteros ou semi-perípteros. A falta de elementos arquitectónicos não permite afirmar, com segurança, se é um templo in antis, com duas colunas adossadas e duas isentas, na fachada, ou um templo prostilo tetrastilo. No entanto, a planta e dimensões do edifício parecem sugerir-nos a segunda hipótese, com quatro colunas isentas na fachada. A ser assim, teria um paralelo muito próximo no templo de Vernègues (GRENIER 1958: 280-281, fig. 75), e a sua possível reconstituição seria a apresentada na Est. 5 .

Evidentemente que, à falta de novos elementos, como já foi referido, esta proposta não passa de uma hipótese de trabalho ${ }^{(n)}$.

Se, tal como propõe Jorge de Alarcão, "as divindades clássicas devem ter sido adoradas em templos de planta igualmente clássica, isto é, templos de celia rectangular precedida de um vestíbulo colunado e assentes num pódio alto, com escadaria na fachada" (AlarCão 1986: 92), este templo tem todas as características para que nele fosse adorado um deus do panteão latino. Não sabemos, contudo, qual.

Durante as escavações foram encontrados vários fragmentos de mármore esculpidos com pregueado de vestes. Também se encontrou uma mão, igualmente de mármore, que pelo tamanho pertenceria a uma estátua feminina cuja altura rondaria os $2,5 \mathrm{~m} / 3 \mathrm{~m}$ (Fots. 8 e 9). É a mão esquerda e segura uma pequena caixa.

${ }^{(10)}$ Esta altura é menor que a actual. Os muros de xisto existentes na face interna das fundações deveriam estar cobertos, uma vez que são parte integrante dos alicerces.

(n) A hipótese de se tratar de um templo in antis não deve ser colocada de lado. Embora a maioria destes templos tenha um pronaos pequeno, em Grand Saint Bémard existe um que tem dimensões semelhantes ao de Almofala: $15 \mathrm{mX} 8 \mathrm{~m}$, com $5 \mathrm{~m}$ de pronaos (Grenier 1958: 532-534, Fig. 167). 
No estado actual das investigações não se sabe qual o tipo de recinto em que este templo se insere: se um forum, se um santuário ou se um local de culto da população de um vicus.

São relativamente poucos os achados arqueológicos de época romana referenciados para a região de Riba-Côa, onde se situa este monumento. Embora a zona possua características orográficas e climáticas semelhantes às do Alentejo, a densidade de ocupação romana parece ser muito menor (ALARCÃO 1988b, II (1): 53-57, Sheet 4a). Tal facto poder-se-á dever mais a uma lacuna de informação do que a um povoamento esparso da região. Existem igualmente dúvidas quanto à sua integração administrativa e territorial, uma vez que "a área entre o Côa e o Águeda, o Douro e a Serra da Marofa, é uma zona praticamente deserta, onde se localiza, todavia, uma povoação romana, importante pelo menos na época visigotica, pois foi então sede de diocese: Caliabria, hoje Castelo Calabre. Não temos quaisquer provas de que Caliabria tenha sido sede de civitas: este território entre o Côa e Águeda estaria integrado noutra civitas, que não suspeitamos por enquanto qual fosse". (ALARCÃo 1988a: 44).

A civitas onde este território estaria inserido poderia, inclusive, ter a sua capital em território actualmente espanhol. A povoação de Caliabria ocupa o cimo de um monte numa zona de relevo muito acentuado nas margens do Douro. As suas boas defesas naturais poderão sugerir um acréscimo da sua importância apenas nos tempos conturbados do fim do Império.

Por outro lado, várias outras povoações terão certamente existido neste território. A grande densidade de vestígios em redor do local onde se ergue o templo; a arquitectura deste, seguindo as regras vitruvianas; e a possibilidade de ali se ter adorado uma divindade latina, permite pensar que terá ali existido uma povoação de certa importância, com uma população já com certo gráu de romanização( $\left.{ }^{12}\right)$.

(12) O fragmento de uma placa de mármore moldurada existente no Convento de Santa Maria de Aguiar (CURADO 1985: 651-652), com paralelo na inscrição CIL II 442, proveniente de Idanha-a-Velha parece atestar o grau de romanização e a opulência da população desta zona. Embora não se sabendo a proveniência exacta da inscrição, esta poderá ter sido encontrada nas imediações da Torre, uma vez que o convento foi proprietário desses terrenos desde o séc. XII. 
Somente a continuação das escavações no local irá permitir a confirmação desta hipótese (13).

\section{BIBLIOGRAFIA}

ALARCÃO, Jorge de, 1986, "A arquitectura romana", História da Arte em Portugal, I, Lisboa, 1986, p. 75-128.

ALARCÃO, Jorge de, 1988a, O domínio romano em Portugal, Lisboa, 1988.

ALARCÃO, Jorge de, 1988b, Roman Portugal, Warminster, 1988.

ALARCÃO, Jorge et ETIENNE, Robert 1977, Fouilles de Conimbriga. 1. L'architecture, Paris, 1977.

AZEVEDO, Pedro A. de, 1910, Documentos de Santa Maria de Aguiar. "Revista Lusitana", 13(1-2), 1910, p. 1-17.

Carvalhosa, A., 1959, Carta Geológica de Portugal Notícia explicativa da Folha 15-D. Figueira de Castelo Rodrigo, Lisboa, 1959.

COUTO, João, 1927, O Convento de Santa Maria de Aguiar em Riba-Côa, Porto, 1927.

CURADO, Fernando Patrício, 1985, Epigrafia das Beiras. (Notas e Correcções - I), "Beira Alta”, XLIV (4), 1985, p. 641-655.

FRADE, Helena 1990, A Torre de Almofala, IV Jornadas Arqueológicas da Associação dos Arqueólogos Portugueses Actas Lisboa, 1990, (no prelo).

GARCiA, José Maria, 1965, Torre das Águias em Almofala-Riba Côa, "Beira Alta", XXIV (2), 1965, p. 223-233.

GRENIER, Albert, 1958, Manuel d'archeologie gallo-romaine. III. l. L'architecture, Paris, 1958.

HAUSCHILD, Theodor, 1986, Investigações efectuadas no templo romano de Évora, em 1986, "Trabalhos de Arqueologia do Sul", 1, 1986, p. 93-98.

MANTAS, Vasco Gil, 1988, ORARIUM DONAVITIGAIDITANIS: Epigrafia efunções

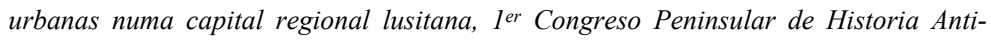
gua. Actas, vol. II, Santiago de Compostela, 1988, p. 415^439.

VITERBO, Fr. Joaquim de Santa Rosa de, 1983, Elucidário das palavras termos e frases... edição crítica por Mário Fiúza, Porto, 1983, Verb. Abbade Magnate.

(13) Cabe aqui um agradecimento a todos quantos, de algum modo, colaboraram neste estudo. Assim, agradeço ao Dr. Beleza Moreira, que, como Director do Serviço Regional de Arqueologia da Zona Centro, me incumbiu do trabalho nesta estação; à Câmara Municipal de Figueira de Castelo Rodrigo, nas pessoas dos seus presidentes e vereadores, pelo entusiasmo que mostraram e pelo apoio que deram aos trabalhos de escavação; ao Dr. José Luís Madeira, que elaborou parte dos desenhos de campo e procedeu à sua atintagem; a José Carlos Caetano, que comigo colaborou nos trabalhos de campo, tendo sido várias as achegas que deu e as reflexões que fez durante a elaboração deste estudo. Pelos incentivos que me deram para a realização deste trabalho, fazendo reparos e sugestões quanto à interpretação do monumento, não posso deixar de agradecer aos professores Jorge de Alarcão e Theodor Hauschild. 
(Página deixada propositadamente em branco) 


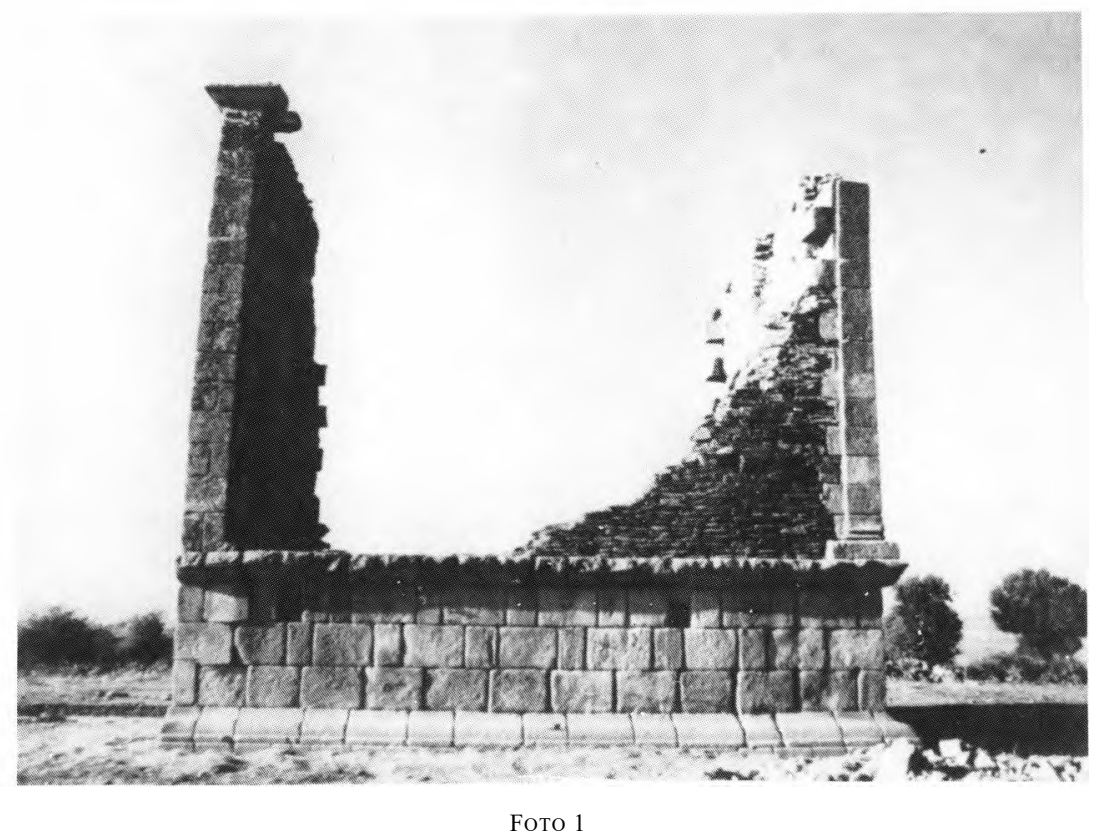




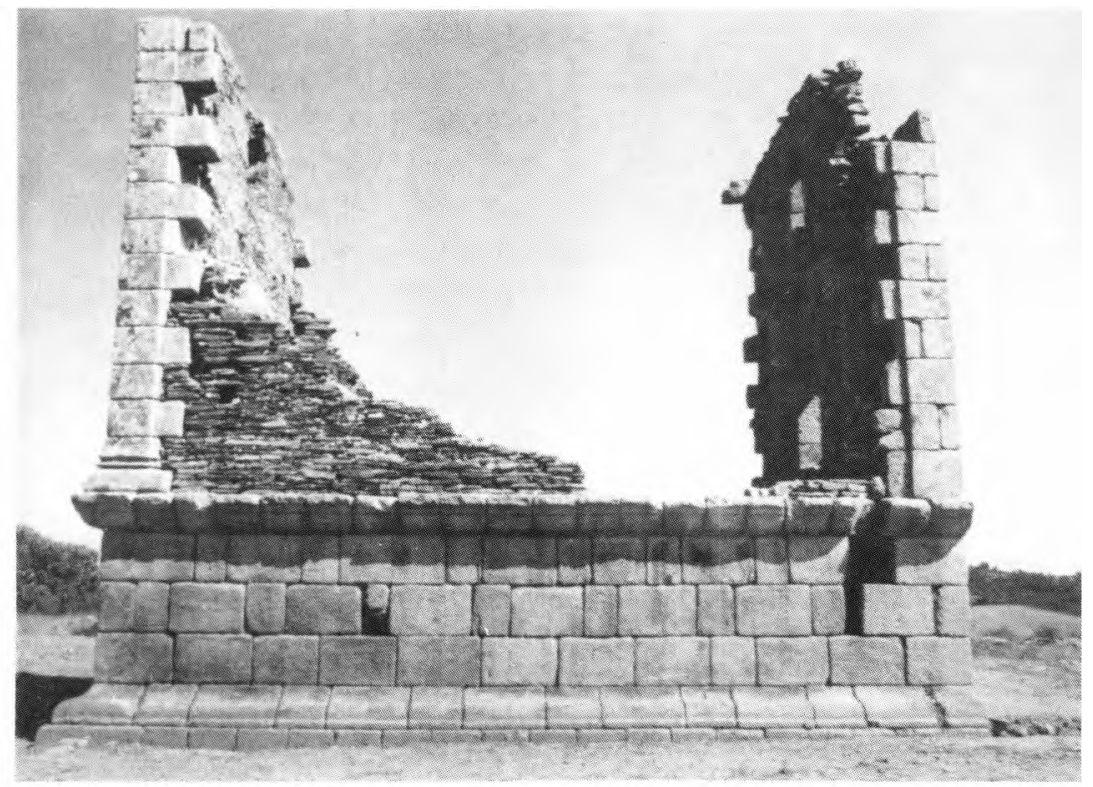

Fото 2 


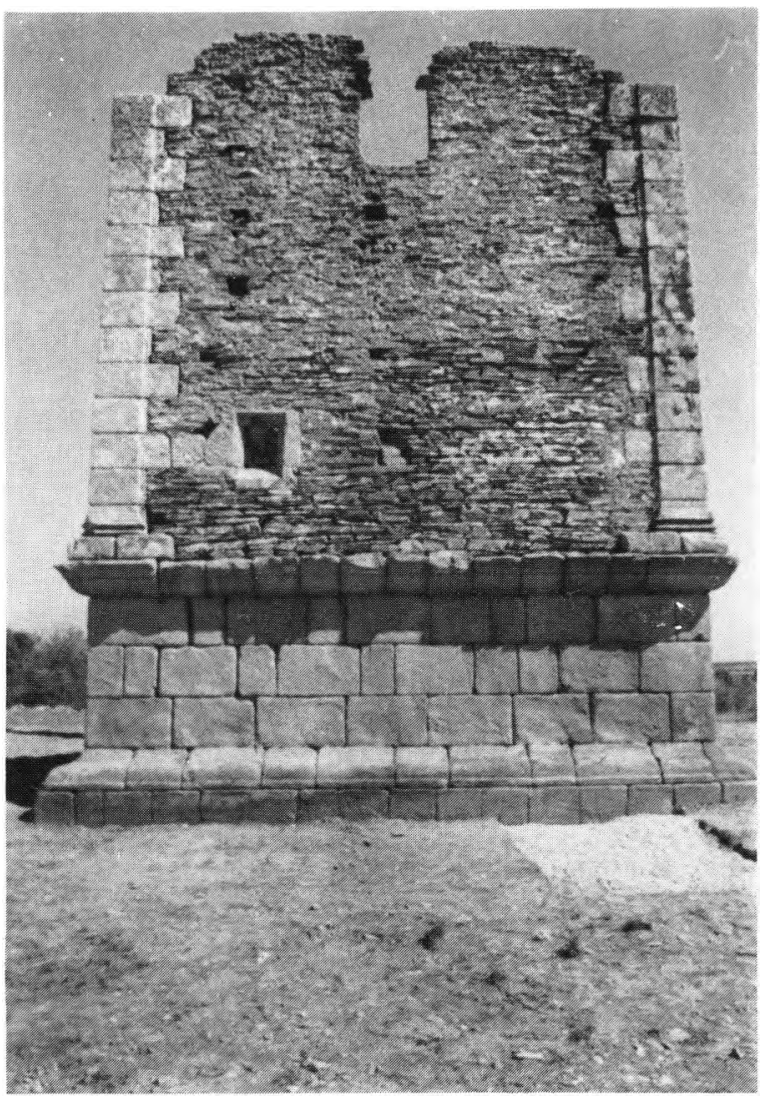

Fото 3 


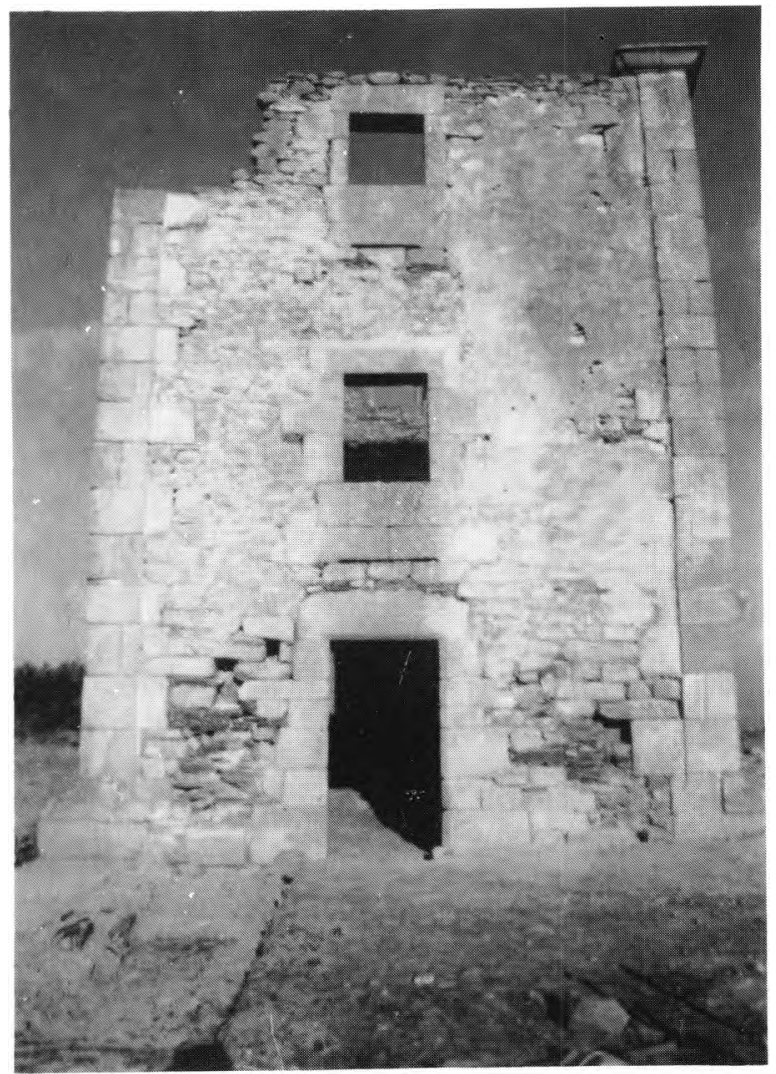

Fото 4 












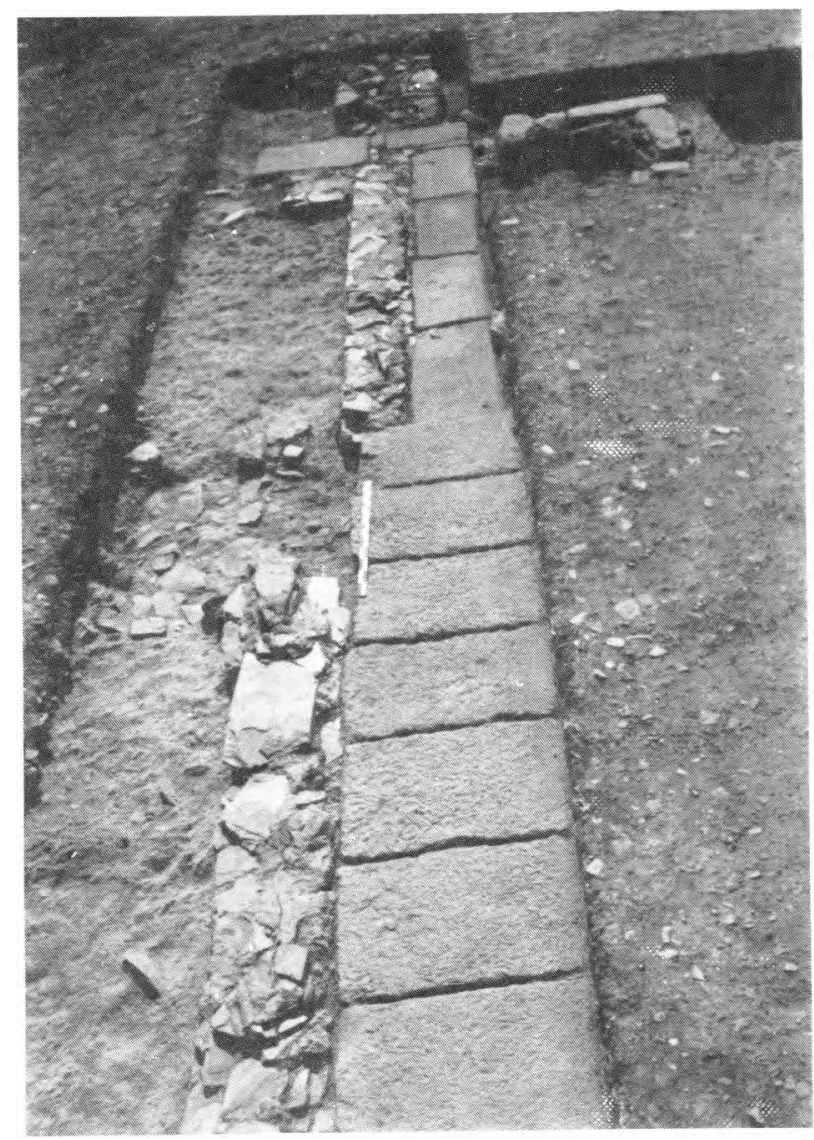

Foto 7 




Fото 8 




Fото 9 
(Página deixada propositadamente em branco) 





(Página deixada propositadamente em branco) 


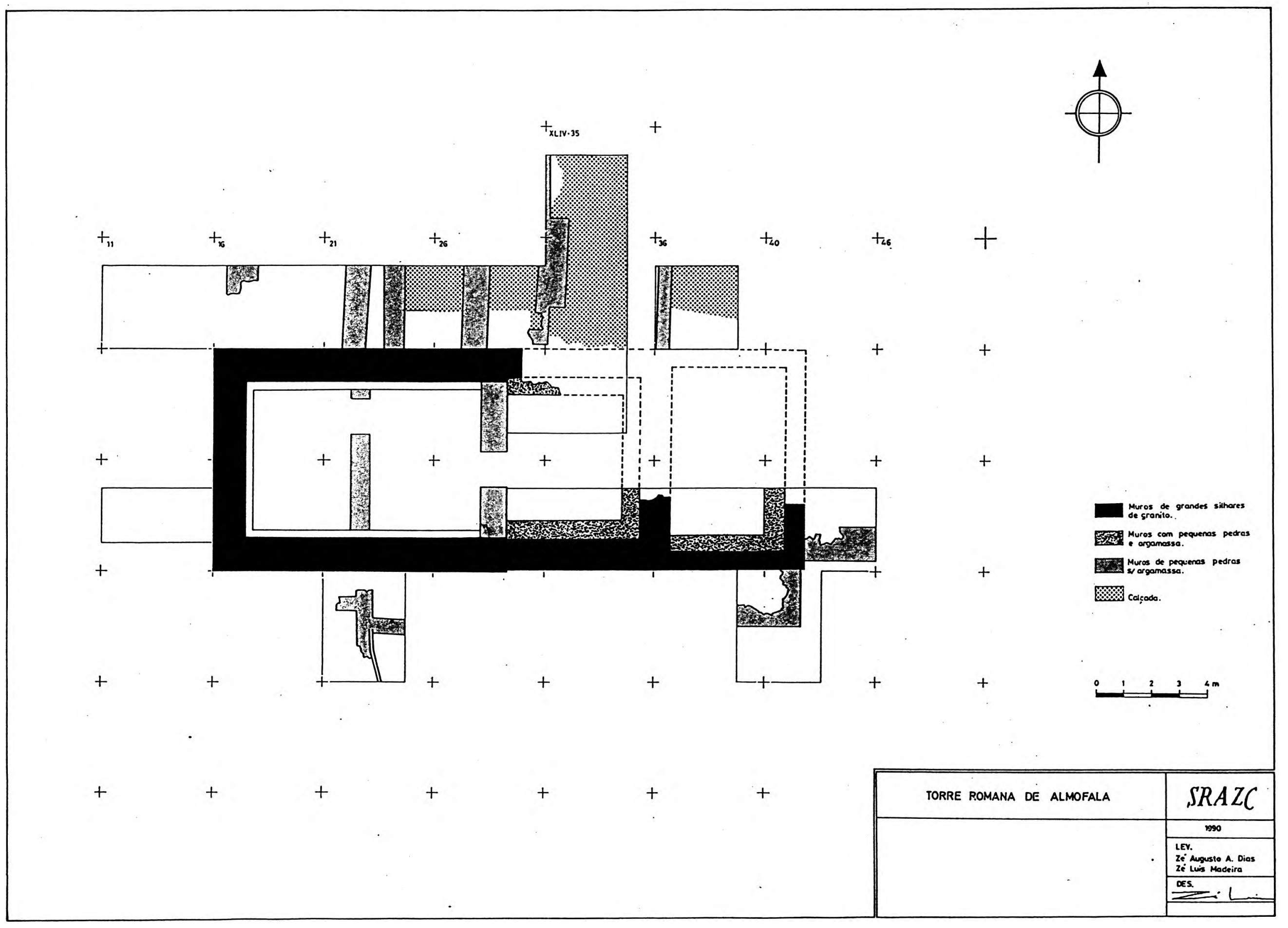


(Página deixada propositadamente em branco) 



${ }^{1} \quad 2 \mathrm{~m}$

ALMOFALA 
(Página deixada propositadamente em branco) 

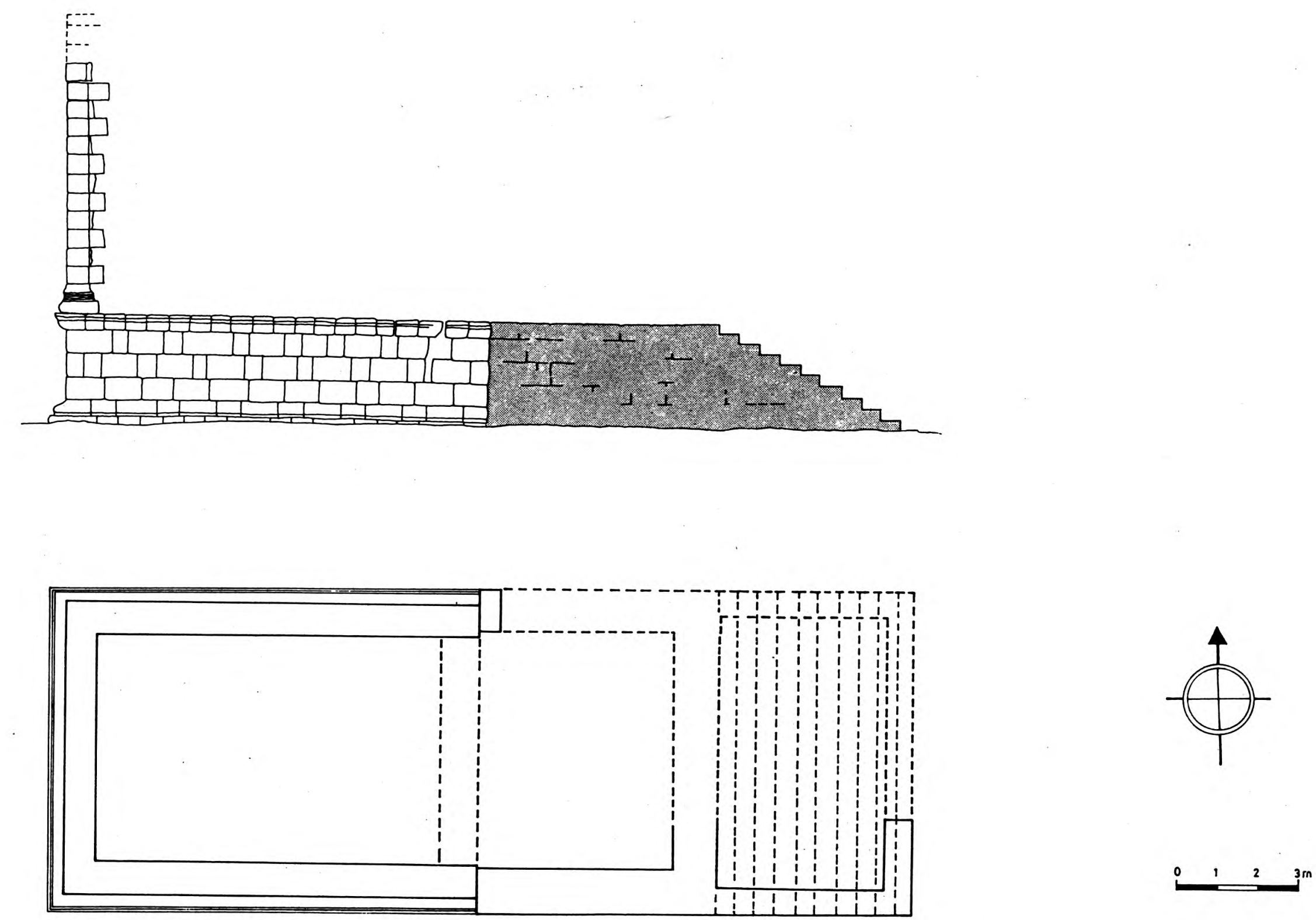

TORRE ROMANA DE ALMOFALA

ALCADO SUL - RECONS STrivicä́O

$\geq$ L


(Página deixada propositadamente em branco) 

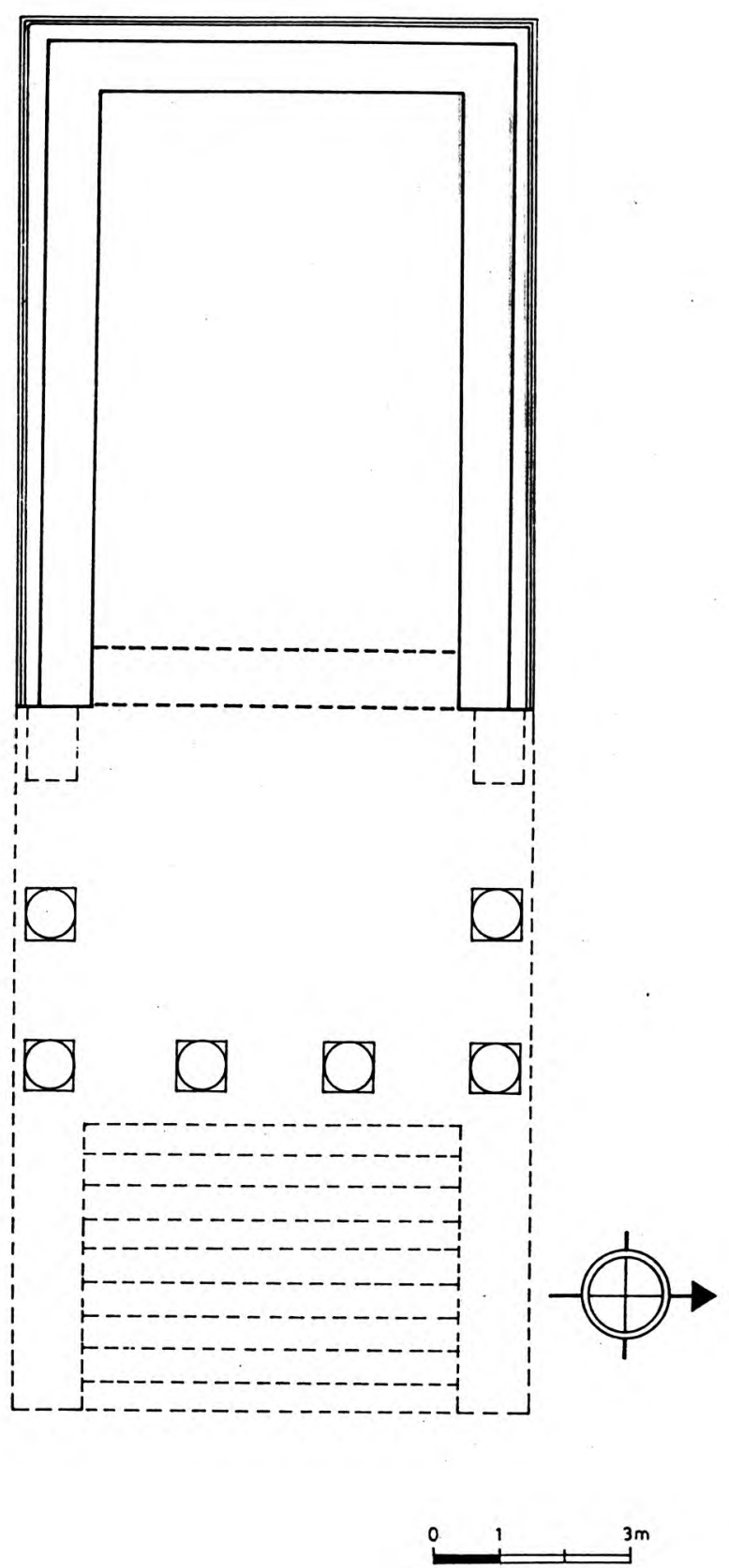
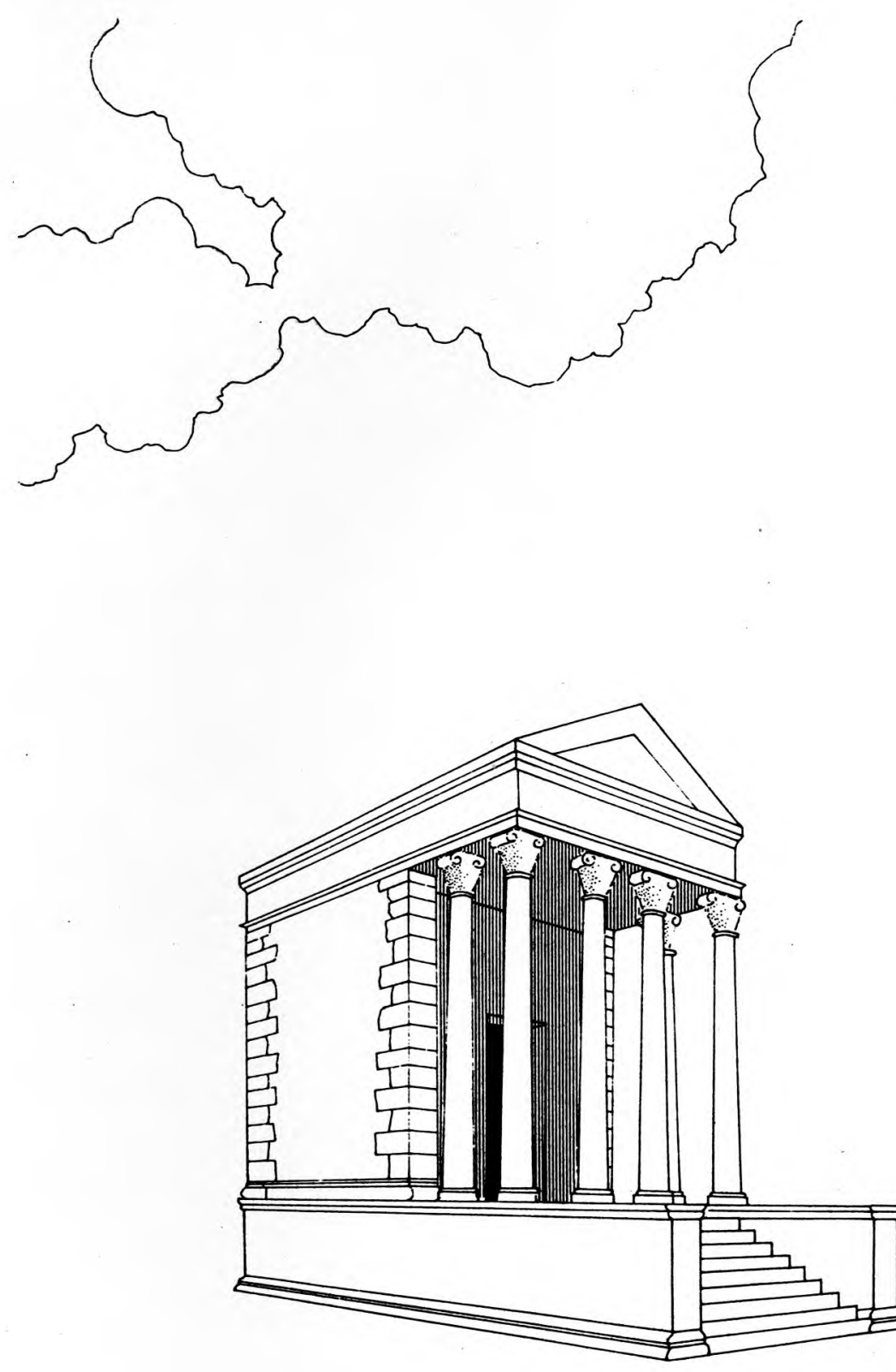

IDEALIZAGāo DO TEMPLO ROMANO

DE ALMOFALA. 